\title{
Poverty and Persistence: A Model for Understanding Individuals' Pursuit and Persistence in a Doctor of Education Program
}

\author{
Amanda J. Rockinson-Szapkiw, Lucinda S. Spaulding, \\ James A. Swezey, and Carolyn J. Wicks \\ Liberty University, Lynchburg, VA, USA
}

\author{
aszapkiw@liberty.edu; Isspaulding@liberty.edu; \\ cwicks3@liberty.edu; jaswezey@liberty.edu
}

\begin{abstract}
The purpose of this systematic grounded theory study was to extend the theoretical foundations of selfdetermination theory (Deci \& Ryan, 1985, 2008), Tinto's (1993) integration model of graduate persistence, and the framework of resilience (Cefai, 2004; Luthar, Cicchetti, \& Becker, 2000) to generate a theoretical model explaining how doctoral candidates from backgrounds of poverty persist through to successful admittance to doctoral candidacy. The proposed theoretical model provides an account for the relationship among significant losses in childhood that are subsequently transformed into positive attributes that motivated participants' pursuit and persistence in a doctoral program. This study produced two new constructs contributing to the empirical and theoretical literature addressing persistence: familial integration and altruistic motivation. With high attrition rates across disciplines, this study makes an important contribution to the theoretical and empirical literature addressing doctoral persistence. Further, understanding the unique phenomena of familial integration and altruistic motivation assists universities in identifying marketing strategies and support services for the population under study.
\end{abstract}

Keywords: Doctoral Education, Poverty, Persistence, Grounded Theory

\section{Introduction}

Researchers and theorists have established that childhood poverty has a negative influence on academic motivation and educational outcomes (Sirin, 2005; Young, Johnson, Hawthorne, \& Pugh, 2011). The effects of childhood poverty reverberate throughout elementary, middle, and secondary school settings and continue to influence post-secondary outcomes (O'Connor, 2009), with the effects compounding over time (Ready, 2010). Individuals from backgrounds of poverty often do not pursue higher education, especially graduate education, as higher education has traditionally been accessed by students from middle to

Material published as part of this publication, either on-line or in print, is copyrighted by the Informing Science Institute. Permission to make digital or paper copy of part or all of these works for personal or classroom use is granted without fee provided that the copies are not made or distributed for profit or commercial advantage AND that copies 1) bear this notice in full and 2) give the full citation on the first page. It is permissible to abstract these works so long as credit is given. To copy in all other cases or to republish or to post on a server or to redistribute to lists requires specific permission and payment of a fee. Contact Publisher@InformingScience.org to request redistribution permission. high socioeconomic backgrounds; however, this trend is slowly changing (Ramburuth \& Hartel, 2010). Educational access is expanding to all socioeconomic backgrounds, especially as colleges and universities offer more online programs (Allen \& Seaman, 2010). The literature provides an explanation of how individuals from a background of poverty persist or fail to persist into higher education, generally focusing on two-year degrees from community colleges and four-year degrees for colleges and universities. 
The purpose of this prior research has been to assist colleges and universities in understanding how to best support persistence among these individuals (Butner et al., 2001; Cabrera \& La Nasa, 2000; Evans \& Schamberg, 2009; Horn \& Chen 1998; Hossler, Schmit, \& Vesper, 1999). Unfortunately, a search of keywords, including doctoral attrition, doctoral persistence, doctoral education, resiliency, resilience, and poverty, using scholarly databases such as EBSCO and Google Scholar, rendered no articles explaining the process that individuals from backgrounds of poverty progress through toward doctoral persistence.

Over the past 40 years, researchers have consistently reported that only $30 \%$ to $60 \%$ of students in doctor of education programs persist (Berelson, 1960; Bowen \& Rudenstine, 1992; Ivankova \& Stick, 2007; Nettles \& Millet, 2006). Given the literature on poverty and education that suggests individuals from poverty backgrounds are less likely to persist, persistence rates may even be grimmer for this population. Understanding how a background of poverty motivates and serves as a resilience mechanism for doctoral persistence can assist university administrators and educators in providing resources and planning curriculum to address the problem of doctoral attrition and promote doctoral persistence.

This phenomenon of doctoral persistence, defined as "the continuance of a student's progress toward the completion of a doctoral degree" (Bair, 1999, p. 8), has been given little attention in the literature (Ivankova \& Stick, 2007; Spaulding \& Rockinson-Szapkiw, 2012), and, in a literature search, no articles were found that addressed doctoral persistence specific to individuals from poverty backgrounds. While prominent motivational and attrition theories (e.g., Bean \& Metzner, 1985; Tinto, 1975) provide a foundation for understanding doctoral persistence among those from backgrounds of poverty, they have been criticized as not applicable to nontraditional, doctoral students (Bean \& Metzner, 1985; McQueen, 2009). These theories have not sought to explain the unique experience of individuals who come from backgrounds of poverty. In fact, Tinto (2006-2007) purported that the current theory provides little value to institutions desiring to address the phenomenon of persistence. Thus, this investigation sought to explain the process in which doctoral candidates from backgrounds of poverty persist through to successful admittance to doctoral candidacy (enrollment in the dissertation process after successful completion of course work and the comprehensive exam), building upon the current theoretical foundations of selfdetermination theory (Deci \& Ryan, 1985, 2008), integration model of graduate persistence (Tinto, 1993), and the framework of resilience (Cefai, 2004; Luthar et al., 2000).

\section{Conceptual Framework}

This inquiry is grounded in theory and research addressing complex relationships among childhood poverty, academic motivation, persistence, and resilience. Deci and Ryan's (1985) self-determination theory (SDT) addresses the concept of motivation, which can be categorized as either intrinsic or extrinsic (Deci \& Ryan, 2008). Intrinsic motivation is behaving for the sake of the behaviour itself, while extrinsic motivation includes motivators that are aimed at obtaining outcomes external to the behaviour. Both intrinsic and extrinsic motivators motivate engagement in an activity (Deci \& Ryan, 2008). For example, a doctoral student may initiate a doctoral degree based on a variety of internal (e.g., pursuing a doctoral degree for the love of learning), and external (e.g., promotion, pay raise, recognition) motivators. The success of this behavior is supported or thwarted by the social-cultural context and how the context supports innate psychological needs (autonomy, competence, and relatedness) (Deci, Vallerand, Pelletier, \& Ryan, 1991). For example, the pursuit of a doctoral degree may be cultivated by feeling of relatedness that family members provide when they verbally communicate support for the pursuance of the degree (Deci \& Ryan, 2000; Deci et al., 1991; Ryan \& Deci, 2000). The volitional behavior may also be thwarted if family members or the community communicate a disdain toward higher education institutions and degrees. The meeting of the psychological needs such as relatedness provides the context to support the motivated behavior and for the likelihood of positive outcomes, in this case, doctoral persistence (Vansteenkiste, Simons, Lens, Sheldon, \& Deci, 2004). While SDT is useful for understanding doctoral candidate motivation for beginning doctoral studies, it is lacking when it comes to explaining reasons for persistence within the educational context. 
Rockinson-Szapkiw, Spaulding, Swezey, \& Wicks

Tinto's $(1975,1993)$ integration theory has been applied and well investigated with regard to doctoral persistence (see Earl-Novell, 2006; Herzig, 2002; Hoskins \& Goldberg, 2005; Ivankova \& Stick, 2007; Spaulding \& Rockinson-Szapkiw, 2012). Tinto's $(1975,1993)$ integration theory explains that persistence is influenced by (a) individual factors including attributes and prior experiences and (b) institutional variables. Familial socialization and growing up in a culture of poverty may contribute to the forming of individual values and habits that interact with institutional variables that help or hinder success (Patterson \& Hastings, 2007).

Candidates from backgrounds of poverty who persist not only through undergraduate degrees and graduate degrees, but also to the point of doctoral candidacy show evidence of resilience. Resilience, most simply defined, is success despite adversity (Cefai, 2004; Luthar et al., 2000). While seminal resilience researchers focused on identifying and generating lists of risk and protective factors (see Garmezy, 1971; Werner, Bierman, \& French, 1971), more recently resilience researchers have recognized that the construct is much more interactive and dynamic than originally theorized (Rutter, 1985). Rutter (1985) argued that rather than looking at resilience as a long list of protective and risk factors, resilience essentially resides in how individuals respond to situations. For example, separation from parents is typically considered a risk factor, but for unaccompanied Sudanese refugee children in northern Kenya, separation from parents helped them form a powerful resilience mechanism that fostered their academic persistence, evidenced through the phrase "education will be our mother" (Spaulding, 2009, p. 127). Thus, it is illogical to categorize any one variable as a risk or protective factor, as it is "process or mechanism, not the variable, that determines the function" (Rutter, 1987, p. 317).

This shift from identifying risk and protective factors to understanding resilience mechanisms (Luthar et al., 2000) led to an emphasis on accounting for cultural and contextual factors in studies of resilience. Clauss-Ehlers (2008) defined cultural resilience as "the way that the individual's cultural background, supports, values, and environmental experiences help facilitate the process of overcoming adversity" ( $p$. 28). Thus, despite the generally deleterious effects of childhood poverty, the resilience framework suggests that the sociocultural context of childhood poverty may play an instrumental role in the development of resilience mechanisms necessary to overcome adversity. For example, exposure to the stressors typically associated with childhood poverty may serve to strengthen rather than weaken an individual's resistance to adversity later in life. Rutter (1985) used the term steeling effects to explain this concept of strengthened resistance to stress as a result of earlier exposure to stress.

With an emphasis on interaction between the individual and resources and stressors in the larger sociocultural context (Clauss-Ehlers, 2008; Luthar et al., 2000), the resilience framework aligns with Tinto's (1993) integration model and further emphasizes the contextual factors and interactions between individuals and their environment when examining the construct of persistence. While SDT (Deci \& Ryan, 1985) addresses motivation and aspiration, Tinto's (1993) theory explains graduate persistence, and the framework of resilience explains the interaction between the internal and external factors that lead to success despite the adversity of growing up in the context of poverty (Cefai, 2004), there is currently no theory or model explaining how doctoral candidates from backgrounds of poverty overcome the unique challenges inherent in poverty and persist to doctoral candidacy.

\section{Literature Review}

Childhood poverty is an epidemic that is prevalent in the United States. One fifth of children in the United States grow up in poverty, and the United States is ranked second for childhood poverty rates in a list of the world's 35 richest countries (UNICEF Innocenti Research Centre, 2012). Poverty negatively affects many aspects of child's life (Duncan \& Magnuson, 2011; Sirin, 2005; Young et al., 2011) that often results in a poor trajectory for adulthood (Ready, 2010). For decades, educators and politicians envisioned education as a minimizer for the effects of poverty since education provides knowledge and skills for success and productivity in adulthood. Unfortunately, this vision is not a reality as the economic gap has been identified as one of the greatest achievement dividers in the United States. A Stanford University 
researcher said, "We have moved from a society in the 1950s and 1960s, in which race was more consequential than family income, to one today in which family income appears more determinative of educational success than race" (Tavernise, 2012, para 4).

Poverty has been shown to negatively influence academic outcomes and adulthood success. Individuals who lived in poverty are less likely to graduate from high school and pursue a higher education degree as compared to those who have not lived in poverty. Thirty two percent of individuals who spend half their childhood in poverty do not graduate from high school as compared to only $6 \%$ of those who have not experienced poverty (Hernandez, 2011). Duncan and Magnuson (2011) found a relationship between household income in which one is born into and adult productivity. Lack of success in adulthood, including pursuing and persisting in a higher education degree, can be accounted for by the negative conditions of growing up in poverty.

While poverty continues to negatively influence higher education degree obtainment, the evolution of online education and the introduction of government policies to make education more accessible is slowly enabling individuals from low socioeconomic backgrounds to pursue and obtain college and university degrees (Allen \& Seaman, 2010; Ramburuth \& Hartel, 2010). Some individuals from low socioeconomic backgrounds pursue and persist to graduate school, obtain master level and doctoral degrees (Allen \& Seaman, 2010; Ramburuth \& Hartel, 2010), and understanding the factors that influence this pursuit and persistence is important for increasing graduate persistence within this population.

Graduate persistence is "shaped by the personal and intellectual interactions that occur within and between candidates and faculty and the various communities that make academic and social systems of the institution" (Tinto, 1993, p. 231). While personal economics and institution provided financial aid factors have been examined in relationship to doctoral persistence, the unique attributes and experience of individuals growing up in the culture of poverty and how these individuals factors interact with the choice to pursue and persist in a doctoral program have not been examined (de Valero, 2001; Gardner, 2009; Jimenez, 2011; Maher, Ford, \& Thompson, 2004; Smith, Maroney, Nelson, Abel, \& Abel, 2006).

The economic challenges for doctoral candidates are very real. Candidates who carry debt from undergraduate studies are less likely to pursue an advanced degree (Perna, 2004). First-generation doctoral candidates finance their degree themselves more than non-first-generation doctoral candidates (Hoffer et al., 2003). These and other financial considerations lengthen candidates' time to degree and decrease the likelihood of degree completion (Terenzini, Springer, Yaeger, Pascarella, \& Nora, 1996). Yet, many candidates persist and complete doctoral work believing future career opportunities will provide financial stability (Gardner \& Holley, 2011). Economic integration, which Wao and Onwuegbuzie (2011) defined as the "degree to which candidate's financial needs are met while pursuing the doctorate" (p. 117), and doctoral persistence have also been studied. However, the literature is inconclusive when it comes to explaining the relationship between financial assistance and persistence. While Earl-Novel (2006) reported that candidates who finance their own studies are less likely to persist, Groen, Jakubson, Ehreneberg, Condie, and Yung Hsu Liu (2008) found that doctoral candidates receiving substantial financial assistance still had low completion rates. Further, some candidates drop out of doctoral work lured by the stability of full time work (Willis \& Carmichael, 2011), while candidates who continue to work full time and take doctoral courses report feeling overwhelmed (Wao \& Onwuegbuzie, 2011). While findings are inconclusive about how finances and economics influence doctoral persistence, research has consistently demonstrated that economic factors influence educational decisions. Further, research that suggests that growing up in a culture of poverty influences the pursuit of and persistence in education further supports the need to investigate the influence of poverty on doctoral persistence. Thus, the purpose of this grounded theory study is to extend the theoretical foundations of self-determination theory (Deci \& Ryan, 1985, 2008), Tinto's (1993) integration model of graduation persistence, and the framework of resilience (Cefai, 2004; Luthar et al., 2000). 


\section{Research Questions}

The following research questions guide this inquiry:

Research Question 1: How does childhood poverty serve as a resilience mechanism with regard to doctoral persistence?

Research Question 2: What intrinsic and extrinsic factors motivate individuals from backgrounds of poverty to pursue and persist in a doctoral degree?

\section{Methods}

This systematic grounded theory (Strauss \& Corbin, 1990) study seeks to explain how doctoral candidates from backgrounds of poverty persist to doctoral candidacy. The sample was drawn from a population of doctoral candidates enrolled in a Doctor of Education (Ed.D.) program at a private, religious, non-profit, liberal arts university in the eastern United States. The university enrolls over 80,000 online and residential, national and international candidates. Approximately 2,000 candidates are enrolled in the Ed.D. program and about $400-500$ of these candidates have obtained doctoral candidacy. The Ed.D. program is a blended program that requires 50 online credit hours and 10 residential credits. The program is fully accredited through the Southern Association of Colleges and Schools (SACS) and the National Council for Accreditation of Teacher Education (NCATE). The doctoral program consists of three stages: (a) the coursework, (b) the comprehensive evaluation, and (c) the dissertation. Participants were purposefully selected from this institution if they met the following study criteria: (a) successfully completed their doctoral course work and passed the comprehensive exam, (b) current enrollment in the dissertation coursework, (c) experienced poverty for a significant part of their developmental years.

Defining a construct like childhood poverty is complex and should be considered multi-dimensionally (Strenze, 2007). Participants eligible for the study were identified through a survey that used four dimensions to assess backgrounds of poverty: (a) parental income, (b) parental employment status, (c) parental education level, and (d) perceptions of child deprivation (going without items deemed to be necessary to children) during a significant part of the developmental years (i.e., at least 5 years between the ages of 0 and 18) (see Table 1).

Table 1. Theoretical Sampling Questionnaire $(N=12)$

\begin{tabular}{|c|c|c|}
\hline Parental Income & Yes & $\%$ \\
\hline $\begin{array}{l}\text { 1. Recall being homeless (residing in a shelter) or living with relatives for an ex- } \\
\text { tended period of time ( }>3 \text { months). }\end{array}$ & 9 & $75 \%$ \\
\hline $\begin{array}{l}\text { 2. Recall receiving public assistance such as free-reduced lunch, food stamps, or vis- } \\
\text { iting a food pantry or food kitchen. }\end{array}$ & 10 & $83 \%$ \\
\hline 3. Lived in rented accommodations most of your childhood. & 7 & $58 \%$ \\
\hline \multicolumn{3}{|l|}{ Parental Employment Status } \\
\hline $\begin{array}{l}\text { 4. Either one or both parents were unwillingly unemployed for several }(>2) \text { periods } \\
(>6 \text { months) of time in your childhood. }\end{array}$ & 4 & $33 \%$ \\
\hline 5. Recall receiving public assistance such as welfare or unemployment insurance. & 6 & $50 \%$ \\
\hline \multicolumn{3}{|l|}{ Parental Education } \\
\hline 6. Neither parent earned a college (2 or 4 years) or university degree & 11 & $92 \%$ \\
\hline 7. Few or no memories of being encouraged to excel in school and go to college. & 6 & $50 \%$ \\
\hline $\begin{array}{l}\text { 8. Few or no memories of parental involvement in your education (attending school } \\
\text { functions, parent-teacher conferences, etc.). }\end{array}$ & 7 & $58 \%$ \\
\hline $\begin{array}{l}\text { 9. Few or no memories of being read to or being assisted with homework when you } \\
\text { were a child. }\end{array}$ & 7 & $58 \%$ \\
\hline
\end{tabular}




\section{Perceptions of Child Deprivation}

10. You had a general awareness of being "poor" compared to your peers during your $12 \quad 100 \%$ childhood.

11. Your friends typically had more material goods/resources than you did growing $\quad 12 \quad 100 \%$ up.

12. You were aware that your neighborhood was "rough" or unsafe.

$6 \quad 50 \%$

After obtaining Institutional Review Board (IRB) approval, we sent an email to all doctoral candidates in the program requesting that they complete the survey and provide contact information and consent to participate in the study if they met the study criteria. The initial survey yielded a response from 124 doctoral candidates. From this sample 117 indicated they were willing to participate and responded to all survey items. Of the 117 who were willing to participate, survey responses were analyzed and doctoral candidates were considered for participation if they indicated "Yes" for 50\% or more of the survey items, with a minimum of one "Yes" response for each of the four dimensions (parental income, parental employment status, parental education level, perception of child deprivation). To ensure maximum variation and a representative sample of the population, gender and ethnicity were considered in the selection of the sample. In accordance with Strauss and Corbin's (1990) suggestion for grounded theory studies, participants were added until theoretical saturation was achieved using the constant comparison method of analyzing each set of data until the theory was well developed and additional iterations of data collection and data analysis failed to generate new findings or further inform the theoretical model. The final sample consisted of 12 participants ( 7 female, 5 male) who were purposefully selected to serve as the theoretical sample for the study as they represented information rich cases (Patton, 1990). Table 1 provides a summary of the survey results for the final sample; Table 2 provides participant demographic data.

Table 2. Participant Demographics $(N=12)$

\begin{tabular}{clll}
\hline Participant & Gender & Ethnicity & Age \\
\hline 1 & Female & Caucasian & $50-59$ \\
2 & Male & Caucasian & $40-49$ \\
3 & Male & Caucasian & $40-49$ \\
4 & Male & Caucasian & $40-49$ \\
5 & Female & African American & $50-59$ \\
6 & Male & Caucasian & $30-39$ \\
7 & Female & Hispanic & $40-49$ \\
8 & Male & Caucasian & $30-39$ \\
9 & Female & Caucasian & $40-49$ \\
10 & Female & Caucasian & $40-49$ \\
11 & Female & Caucasian & $20-29$ \\
12 & Female & Caucasian & $40-49$ \\
\hline
\end{tabular}

\section{Data Sources}

Data was collected via survey (see Table 1) and semi-structured interviews (see Table 3). The interview questions were derived from a review of the empirical and theoretical literature related to poverty, SDT, resilience, and doctoral persistence. The interviews were pilot tested with an individual meeting the study criteria (but not included in the final sample) to ensure clarity and comprehension prior to interviewing study participants. For consistency of data collection, all interviews were conducted and recorded by one researcher with subsequent verbatim transcription by two research assistants for analysis purposes. 
Childhood $(0-18$ years $)$

1. Please describe your childhood, from birth to 18 years old.

2. Please describe your family's employment and economic situation when you were growing up.

3. In what ways did your parents play a positive or negative role in your education as a child?

4. Please describe the character traits and values that were modeled for you as a child.

5. Are there any individuals other than your parents who played a prominent role in your childhood? Please explain.

6. Looking back, are there any events in your childhood that you feel are responsible for shaping who you are today?

Adulthood

7. Please describe your transition from being a teenager to becoming an independent adult.

8. What was your experience moving into higher education?

9. Looking back, can you identify any specific turning points or experiences in your life that pointed you to the professional and academic path that you are on today?

Doctoral Persistence

10. What is your primary motivation for earning a doctoral degree? What are your secondary motivations?

11. What factors did you consider and/or barriers did you overcome before beginning this degree?

12. What are your goals for the future?

13. What strategies have you employed to help you persist to where you are today?

14. To what do you attribute your educational successes?

15. What are your fears associated with the dissertation process? How do you plan to or how are you currently addressing them?

16. If you could impart just one message to your own children (or the next generation) when it comes to education, what message would that be?

\section{Data Analysis}

Following Strauss and Corbin's (1990) systematic grounded theory procedures, we analyzed the data, including informal data analysis by memoing and formal data analysis by open coding, axial coding, and selective coding to develop a grounded theory. Per Strauss and Corbin, memoing was used throughout the data collection and analysis process to record initial hypotheses and insights on the part of the researchers. Open coding consisted of systematically reviewing statements and words from all data sources and creating conceptual labels or in vivo codes for each concept. As data collection and analysis progressed, concepts were compared across data sources and eventually grouped into categories during the process of axial coding. Finally, selective coding was used to generate a theoretical model explaining how doctoral candidates from backgrounds of poverty persist to admittance to doctoral candidacy.

Lincoln and Guba's (1985) criteria for establishing trustworthiness in qualitative investigations was employed. Credibility and dependability were addressed though data triangulation (questionnaire, interviews, researcher memos), member checking (of interview transcriptions and the final theoretical model), and peer review. 


\section{Findings}

The findings are presented thematically in relationship to the research questions and are followed by a theoretical model (see Figure 1) illustrating how doctoral candidates from backgrounds of poverty persist to doctoral candidacy. Research question one addressed the function of childhood poverty as a resilience mechanism with regard to doctoral persistence. Analysis of interview data revealed two prominent themes in the participants' narratives about their childhood: (a) material loss and (b) relational loss. It must be noted that childhood poverty is complex and multi-dimensional (Strenze, 2007) and while the following themes of material and relational loss are presented linearly, they are inextricably linked, each interacting and interfacing throughout childhood.

\section{Material Loss}

Though decades removed from their childhood at the time of the interviews, participants vividly recounted material loss experienced as child. Loss ranged from loss of furniture and utilities to loss of homes. While a few participants acknowledged having little awareness of their family's economic state as children ("it was normal to get up and go and live somewhere else and it was normal to have to stay wherever you could until you could find another place to stay"), most were acutely aware of their situation. One participant related, "I was always painfully aware that we didn't have basic requirements. Like utilities would be cut off occasionally, there wasn't food in the house; we would go to school with no lunch." Many participants classified their neighborhood as "the ghetto" or "the projects."

While several participants' parents were "too proud" to accept public assistance "because there was a really big stigma attached," most participants easily recounted times in their childhood where their family relied on food stamps, "commodities," or qualified for free/reduced lunch. One participant related, "I don't remember a time in my life where we weren't on food stamps, or we weren't on WIC [women, infant, and children program] or something, some sort of assistance, and always reduced lunch or free lunch...." Even as children, the participants experienced the stigma associated with public assistance; one participant acknowledged, "we tried to hide the fact that I was given a ticket [for free/reduced lunch] but you really couldn't; everybody knew what it was."

While growing up with material needs and material loss had significant effects on the participants' developmental, personal, and professional motivations in life, they were even more profoundly affected by the relational deficits in their lives.

\section{Relational Loss}

While two participants characterized their childhood as relatively stable with two parents in the home, the remaining participants $(n=10)$ experienced significant disruption to the family unit as a result of (a) divorce, including parental absence and abandonment, (b) death, and (c) exposure to drug, alcohol, and physical abuse. These stressors in their sociocultural environment also prematurely propelled several participants into adulthood.

\section{Divorce}

Divorce emerged as a prominent theme in participant discourses, with eight of the 12 participants citing divorce, separation, or a parent "leaving." For some, the separation and subsequent divorce happened when they were quite young. For others, it marked a significant event in their childhood. One participant described his parents' divorce when he was 16 as "the most poignant moment" and "most dominant" event in his childhood. Despite working two jobs, after the divorce his mother became homeless and he went to live with his grandparents.

Several participants experienced the pain of parental abandonment prior to divorce, with ambiguous loss (see Boss, 2004) serving as a subtheme. One participant painfully noted, "When I was two...my daddy 
left my mother with three children, with three little girls." She went on to share, "I would ask my mother ... 'where's my daddy?' And usually ... she would tell me when he was coming home but this time she said, 'I don't know." Another participant was only three years old when her mother dropped her and her sisters off with their grandmother. Though her mother returned when she was six, she died a year later, and the girls were raised for a period of time by their stepfather, before being removed from his care due to abuse. Reinforcing the theme of ambiguous loss, another participant never met his father as he was a "60s love child."

Though their parent(s) were in the home, several participants referred to parental absence, with frequent memories of being left alone to fend for themselves or care for younger siblings while parents worked late shifts or second jobs. A participant who lived with her abusive stepdad after her mother died recollected, "Even at seven and eight years old, ya know, he was pretty absent a lot of the time and I cooked dinner and did laundry and did all those things."

\section{Death}

Death was a prominent theme in participants' childhood and adolescent years. Similar to divorce, the passing of a parent or loved one marked a significant event in childhood. One participant noted that her grandmother's death when she was five was "very traumatic." Another accounted, "Definitely my mom passing away was a huge one...just because the...responsibility and maturity that I had to have at seven and eight years old is not normal ... and so that kinda definitely shaped who I was." Recounting her father's death from AIDs when she was 17, one participant shared, "his death really sent me...emotionally to a different place um, I really didn't care about life anymore; I was very depressed." For another participant, death was not one single event, but a general theme: "everybody around me was dying, all my friends were dying, they were dying from drug overdoses, they were dying from car wrecks..."

\section{Use, abuse, and addiction}

Substance use and abuse, addiction, and physical abuse often occurred simultaneously within the household and appeared to be generational. The participant whose mother abandoned her at three and died when she was seven noted, "My father was abusive and so, they [parents] were both alcoholics and did drugs and those kinds of things." After being removed from her abusive stepfather, she went to live with her grandparents, "and the same-old, same-old, my grandfather was still...ya know, couldn't keep money because he had a gambling addiction and an alcohol addiction." Referencing his father's alcoholism and physical abuse, another participant declared, "I can't stand him and I'll never forgive him. ... he'd beat the crap out of me one night and I'd have to go to school the next day and not tell anybody about it."

\section{Coping Mechanisms}

While material and relational loss were salient themes, the participants were personally transformed as a result of their exposure to the stressors associated with childhood poverty. Their individual responses to the stressors in their sociocultural environment (Clauss-Ehlers, 2008; Luthar et al., 2000; Rutter, 1985) and consequential personal transformation in the face of adversity (Grotberg, 2003) led to resilience. While alcoholism, abuse, death, abandonment, divorce, and the general instability associated with homelessness would typically be considered risk factors for the participants, they served as resilience mechanisms, that is, coping mechanisms and catalysts for personal transformation and the discontinuation of patterns modeled for them as children.

\section{Self-reliance}

Being unable to consistently rely on the adults in their lives required the participants to become independent and self-reliant. Further, the stressors in their lives propelled them into premature adulthood. When asked to describe their transition into adulthood participants made statements like, "I don't know if I was ever a teenager," or "I was kind of grown up as a teenager." The participant whose parents divorced when 
he was 16 stated: "Transition happened overnight. . I felt pressured on myself to, you know, contribute." One participant was emancipated as a teenager, another become a ward of the state, while another related, "Even at nine I started to feel a sense of responsibility for caring for people uh in my life and sort of a sense of responsibility and commitment to my family."

Participants learned at a young age the importance of budgeting and hard work. One participant related, "If there was a field trip or something in school then um...I just wouldn't eat lunch so that I could go on the field trip by saving up money." When describing their childhood ( $0-18$ years) most of the participants noted working part time jobs, several began working as early as 12 or 13 . One participant simply explained, "I needed to have a job to provide for myself."

While the stressors associated with childhood poverty necessitated self-reliance and ignited in individuals the determination to discontinue the negative patterns experienced in their childhood, each at some point came to recognize the need to "get out." For three participants, enlisting in the military provided a way "to climb out" of the confines of poverty. Collectively these participants credited their military service with providing a sense of community and reinforcing or instilling in them the importance of discipline and a strong work ethic.

In addition to developing a strong sense of self-reliance, two factors influenced and supported the participants' self-determination to discontinue the patterns modeled in their childhood: (a) significant individuals and (b) coming to a personal faith were instrumental in personal transformation.

\section{Positive significant individuals}

Each participant easily identified one or two individuals who played an instrumental role in demonstrating or encouraging in them the development of positive traits and values. For some, it was an extended family member like a grandparent, aunt, or uncle who modeled loyalty, integrity, hard work, organization, personal discipline, or "seeing your commitments through." For others it was a teacher, athletic coach, or band director who was "caring," "showed an interest," or "kept his word." Two participants noted teachers who recognized their academic potential. The prominent theme with regard to teachers was high expectations coupled with care: "[They] demanded excellence but were caring and concerned about us.... persistent and caring." The predominant theme for influential family members was quality time - just being there for them (e.g., playing games, reading together, attending extracurricular and sporting events). It is significant to note that none of the participants cited a parent as a significant individual who affected their lives in a significantly positive manner. Parents were cited as negative examples motivating personal change (e.g., "I wanted to be so far from being the person I remember [my mother] being when I was a child;" "All the negativity motivated me to be someone different").

\section{Faith}

When asked to identify turning points or specific events in their life responsible for where they are today, $50 \%(n=6)$ of the participants immediately cited their personal faith.

The participants who identified their personal faith as significant pinpointed the precise age when they "became a Christian" (age six), "accepted the Lord at13," "saved at 16." Two participants referenced "rededicating" their life or being "reborn" as adults ( 23 and 26 years old respectively).

\section{Education: "The Way Out"}

A growing sense of self-reliance, bolstered by supportive individuals and/or a growing faith, seemed to cultivate in the participants the self-determination to transcend their circumstances and find a way out. A few participants learned from their parents $(n=3)$, but most came to the realization on their own $(n=9)$, that education was "the way out" of poverty. One of the participants who described her parents as "positive" toward higher education emphasized, "We needed to go to college, to get a college education because that was our ticket out of poverty. That was gonna be our ticket into the middle class; that was 
Rockinson-Szapkiw, Spaulding, Swezey, \& Wicks

gonna be our ticket into our career." A participant with severe arthritis was resolute: "I always knew that if I wanted to be living independent and successful I would have to pursue a higher education."

\section{Doctoral Motivation and Persistence}

The second research question helped to explain the path participants took from pursuing a bachelor's degree to a doctoral degree; it addressed the intrinsic and extrinsic motivations for pursuing a doctoral degree for these individuals from backgrounds of poverty. According to Ryan and Deci (2000),

Motivational forces that are innate, or intrinsic needs, are assumed to be essential for everyone, but motivational forces that are acquired will vary in strength as a function of the circumstances in which they were acquired. It is the strength of these latter motivational forces that are important for predicting their consequences. (p. 250)

The participants in this study experienced significant relational and material loss during their childhood years. These relationally and materially impoverished circumstances cultivated in each participant the motivation to transcend their sociocultural environment. As Deci and Ryan (2000) elucidate, motivational forces vary in strength depending on the circumstances from which they are generated. For the study participants, it seemed that they were more than simply motivated, but rather were compelled to continue. One participant stated, “Once I started my master's degree. I just wasn't gonna stop. I don't know I just kept on going." Another noted, "I was incomplete without getting a doctorate." And a third participant shared, "It's the highest you can get so I won't be satisfied until I have that."

Each participant felt strongly compelled to pursue a doctorate, but when asked what their primary motivation was for earning the doctorate responses were split equally between intrinsic $(n=6)$ and extrinsic $(n=$ 6). Intrinsic motivations included feeling "called to do it," the love of learning, a personal accomplishment or personal fulfillment, or just never feeling "finished without it." Extrinsic motivations included higher pay, opportunities for career advancement, and the title and recognition associated with the degree.

While some motivations were clearly intrinsic (e.g., personal fulfillment) and others extrinsic (e.g., seeking recognition), there was an additional set of motivations that did not fit neatly into either category, but rather, were altruistic in nature. Based on this study, we define altruistic motivation as the motivation to do something selfless in order to advance others' means, opportunities and social, emotional and cognitive well-being. Statements from participants reflecting such motivations included, "I truly aspire to make a positive impact in the lives of the people I work with and the candidates of our school," "I want to make a difference," and "I want to give back." Participants were also motivated to serve as a model and exemplify for the next generation the traits perhaps they wish were modeled more frequently in their own childhood: To "be a respected individual. . . . build a reputation for being of high character and ethics" and "I really want to set the bar for my family and not only my immediate children but my extended family, my nieces my nephews."

\section{Material and relational provision}

While there may be a tendency to elevate intrinsic motivations over extrinsic, it is significant that a number of participants were motivated by career advancement and the associated financial incentives. Considering the sociocultural context the participants grew up in, it should not be surprising that participants were strongly motivated to provide financially for their families. However, the concept of relational provision emerged as the central theme across participants.

Participants were acutely aware of the time involved in pursuing a doctorate and were resolved to ensure that pursuing the degree did not cause them to neglect their loved ones. In order to prioritize family, one participant eliminated her social life. She explained, “...so that I can dedicate my time to my children and to my husband, because that's really important, I didn't want this to affect them." Discussing her decision to postpone earning her doctorate until the end of her career instead of the middle, one female participant related, "I don't regret it a bit, spending time with my family and children while they were growing." Dis- 
continuing patterns of absence and abandonment were important to the participants. One participant explained, "I would say the biggest obstacle is finding that balance between progressing at the pace that I want to and trying to be involved with my kids, you know, in a way that I didn't have as a child."

\section{Doctoral challenges and persistence strategies}

In addition to a fear of neglecting loved ones, time and financial constraints, along with the fear of not finishing, were the primary challenges cited. However, participants were motivated and determined to persist and cited a range of strategies for addressing these challenges including faith, and organizational, motivational, and relational strategies. Personal faith was a prominent theme-employing prayer and persisting in order to respond to a sense of being called. Participants identified a range of organizational strategies including (a) time management ("blocking out time," "working ahead," and "saying no" to additional obligations); (b) self-discipline and routine ("my biggest strategy is to stay in my office with no distractions"); and (c) using lists and calendars ("I'm ridiculously organized. I have a date book. ... I plan out the week in all different colors"). Sacrificing sleep and sacrificing a social life were also strategies employed. Cognitive appraisal strategies included looking forward ("I Imagine myself . . having it [the dissertation] completed") and self-talk ("I said, even though I'm gonna delay, I'm never gonna quit. I'm gonna always get back in there, get back into the course"). Relational strategies included spousal support ("A supportive wife. She's very understanding. She realizes when I'm under stress and tries to help me") and social integration with peers and faculty in the doctoral program.

\section{Theoretical Model}

Figure 1 presents a theoretical model illustrating how doctoral candidates from backgrounds of poverty transformed childhood risk factors (e.g., material and relational loss) into resilience mechanisms (e.g., self-reliance) that influenced their motivation to begin doctoral studies and determination to persist to successful admittance to candidacy. 


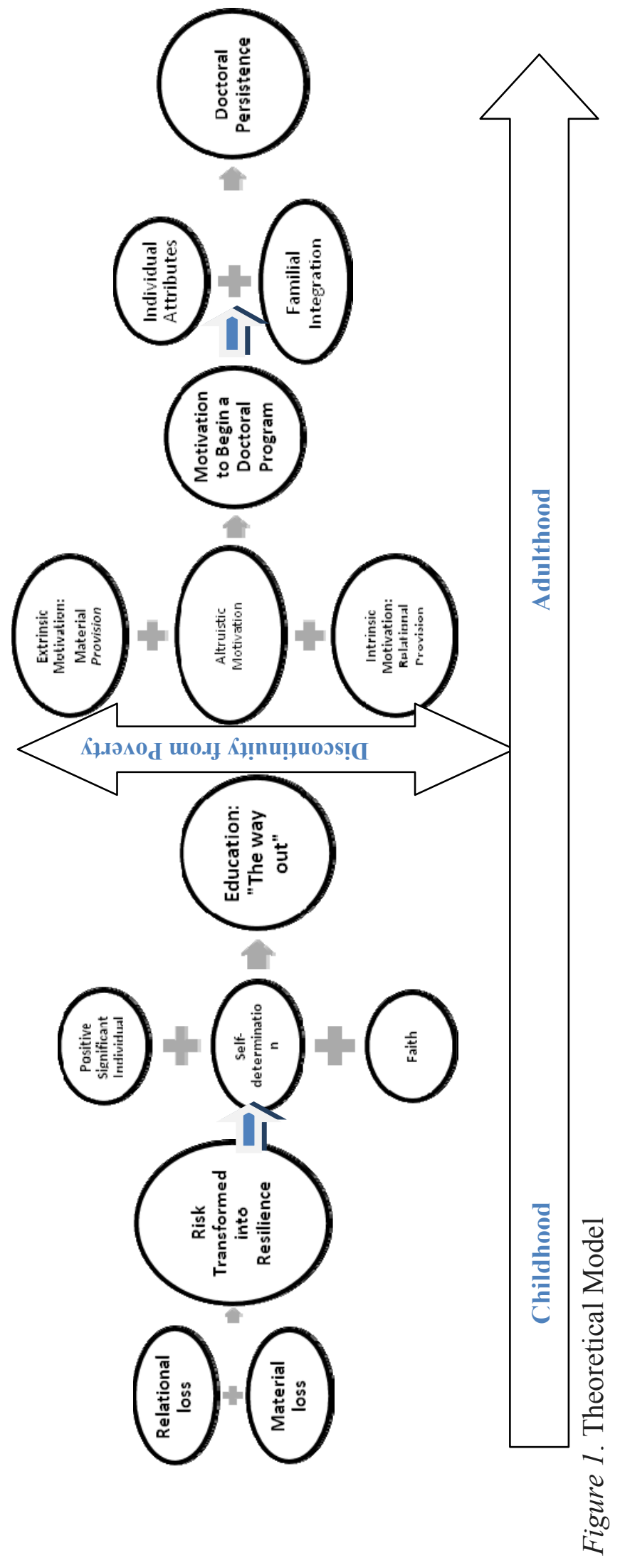




\section{Discussion}

Data analysis revealed that the concept of resilience in doctoral candidates was directly influenced by the material and relational losses experienced as a result of growing up in poverty. The losses, a result of their sociocultural environments (Clauss-Ehlers, 2008; Luthar et al., 2000; Rutter, 1985), necessitated that these doctoral candidates' developed self-reliance at an early age, a characteristic later deemed central to persistence in higher education and a doctoral program. The losses also motivated a determination to discontinue the negative patterns associated with poverty- to "get out." This growing sense of self-reliance and determination was strengthened by many factors, with the most salient (or prominent/significant) being (a) a significant individual and (b) a personal faith. And, at some point, within each of the participants' lives, higher education was recognized as the avenue in which they could "get out" of poverty; that is, discontinue generational patterns of poverty. Pursuit of a doctoral degree, in alignment with SDT (Deci \& Ryan, 1985), was both intrinsically and extrinsically motivated. Both types of motivation appeared to be given equal attention and importance thus, supporting the proposal of SDT that there are various types of extrinsic motivation that are agentic in nature (Deci \& Ryan, 1985). This is in contrast to the classical literature that suggests that extrinsic motivation is impoverished in comparison to intrinsic motivation when it comes to academic achievement (deCharms, 1986).

Candidates were determined to purse a doctoral education because of their own inherent interest in doing so or enjoyment of learning. Altruism was also a key motivation. However, candidates were also motivated to pursue a doctoral degree because of a separable outcome (Deci \& Ryan, 1985), especially a financial one. Having grown up in poverty and been provided with examples of family devotion to provision, participants were highly motivated to provide financially for their families. Interestingly, and in contrast with what the literature says about many candidates entering doctoral programs (Rudestam \& Newton, 2007), many of these candidates entered or chose to postpone their entrance into a doctoral program based on their acute awareness of the hard work and time away from family that it would take to pursue and finish a doctoral degree. Since discontinuing patterns of absence and abandonment was important, candidates postponed the degree or made intentional decisions to relief themselves of responsibilities prior to entering the program. This was to ensure that they did not neglect their spouses, children, and extended family.

The candidates attributed their doctoral persistence to a number of attitudes and coping strategies. These persistence strategies include strength derived from faith and relational supports. These findings are consistent with existing literature (Lott, Gardner, \& Powers, 2009; Price, 2006; Spaulding \& Rockinson-Szapkiw, 2012). However, in contrast with doctoral persistence literature (de Valero, 2001; Herzig, 2002; Hoskins \& Goldberg, 2005; Jimenez, 2011; Spaulding \& Rockinson-Szapkiw, 2012) and attribution theory (Tinto, 1993) that suggests the importance of social integration into the university for persistence, these candidates did not significantly attribute integration into the university as important in their persistence. In fact, some did not attribute university integration as important at all.

It was the attributes derived from experiences in poverty that assisted candidates in persisting. Self-reliance and hard work were central to their doctoral persistence. Key components related to self-determination, such as inner strength derived from cognitive appraisals (e.g., positive selftalk and positive thinking), self-regulation and organizational strategies for goal performance, and self-endorsement of personal behavior or knowledge of internal locus of control (Ryan \& Deci, 2000, 2006, 2008a; Ryan \& Niemiec, 2009), were also essential aspects of persistence. Familial integration also provided support for intrinsic motivation to persist and incentive to complete the degree that was valued by the family and had the potential to provide means and opportunities for offspring (Deci \& Ryan, 2000; Deci et al., 1991; Ryan \& Deci, 2000). 


\section{Theoretical Significance}

There is currently no theory or model explaining how doctoral candidates from backgrounds of poverty overcome the unique challenges inherent in poverty and persist into doctoral candidacy. Further, no research has examined whether these theories are applicable to the unique processes that this population progresses through in order to be academically successful. This research provides a "novel and fresh slants on things" (Strauss \& Corbin, 1990, p. 19). And, it both confirms and disproves elements of the three theories used to frame this study (see Figure 1). Resilience theory explains the interaction between the internal and external factors that led to success despite adversity (Cefai, 2004). SDT (Deci \& Ryan, 1985) addresses motivation to pursue doctoral education. While Tinto's (1993) integration theory has consistently explained graduate persistence in previous research (de Valero, 2001; Gardner, 2009; Jimenez, 2011; Maher et al., 2004; Smith et al., 2006), Tinto's (1993) presupposition that graduate persistence is "shaped by the personal and intellectual interactions that occur within and between candidates and faculty and the various communities that make academic and social systems of the institution" (p. 231) did not explain doctoral persistence within this unique population.

The doctoral candidates from poverty backgrounds had the capacity to successfully adapt in spite of growing up in adverse conditions (Masten, 1994). They achieved more favorable outcomes, the pursuit of and persistence in a doctoral degree, than what was expected from individuals growing up in poverty (Masten, Best, \& Garmezy, 1990). The interactions between the individual and their resources and stressors within their socio-cultural backgrounds of poverty served to explain the development of resilience, and specifically, in this study, provide a rationale for, and a better understanding of, the pursuit of and, ultimately, persistence within a doctoral program (ClaussEhlers, 2003). Consistent with recent resilience models and in affirmation of the importance of resilience mechanisms over protective factors (Luthar et al., 2000; Rutter, 1985), resilience arose from how the doctoral candidates' managed situations and made decisions, influenced by early childhood experiences and highly dependent upon cultural and contextual factors. This created "a chain of indirect linkage that foster[ed] escape" (Rutter, 1985, p.608) or the "way out" of poverty.

This study further reinforced the importance of the theoretical concepts of steeling effects (Grotberg, 2003; Rutter, 1985) and turning points (Doll \& Lyon, 1998; Rutter, 1999). The experiences of loss (e.g., death, divorce, abandonment, disease) and abuse served to strengthen each doctoral candidate. More specifically, they were "transformed by experiences of adversity" (Grotberg, 2003 , p. 27); that is, they responded to adversity by using it as a catalyst for personal change by identifying patterns from their childhood, consciously discontinuing them, and transforming adverse experiences into resilience mechanisms (e.g., self-reliance and a strong work ethic), which later positively influenced their ability and determination to persist through to candidacy in a doctoral program. Consequential to the development resilience was also "empathy and compassion" (Grotberg, 2003, p. 202), which later resulted in the development of altruism and became a primary the motivation to pursue a doctoral degree. Turning points (Rutter, 1999) served to break the negative cycles of poverty and supported a more positive lifespan trajectory. Relational events (e.g., the establishment of a positive relationship with a role model) and a commitment to faith reinforced attributes of self-reliance and determination and opened up education as a "way out" of poverty. The educational opportunity to attend a college or university in either young or middle adulthood was monumental in shifting these candidates from negative life trajectories toward more positive ones, and which ultimately resulted in the pursuit of doctoral education.

SDT purports that social contexts support human motivation and action (Deci \& Vansteenkiste, 2004; Ryan \& Deci, 2000). When social contexts support innate psychological needs and all three innate psychological needs are met (autonomy, competence, and relatedness), the likelihood of positive outcomes improves (Deci et al., 1991). Candidates were determined or felt compelled to pursue a doctoral degree (Black \& Deci, 2000) for a number of reasons, one reasoning being the 
simple pleasure or challenge of pursuing it. Due to circumstances, often a result of growing up in poverty, the candidates developed skills (e.g., self- reliance, organizational strategies) that provided them with sense of competence to pursue the degree (Deci et al., 1991). This was cultivated by feeling of relatedness that the family often provided (Deci \& Ryan, 2000) through communicating support to pursue the degree (Deci \& Ryan, 2000; Deci et al., 1991; Ryan \& Deci, 2000). The meeting of these psychological needs motivated the pursuit of the doctoral degree and provided the context for the likelihood of positive outcomes (Vansteenkiste et al., 2004) and motivation for doctoral persistence (Mason, 2012). Intrinsic motivation coupled with extrinsic motives associated with a doctoral degree, such as pay, opportunities for career advancement, and recognition, further served as motivation to pursue the doctoral degree. Although intrinsic and extrinsic motivation was central to understanding the reason that candidates pursued the degree, a tertiary motivation, which we termed altruistic motivation, was also a motivator. While research has suggested that a relationship exists between SDT's conceptualization of motivation and empathy (Roth, 2008; Ryan \& Connell, 1989) and prosocial behaviors (Pavey, Greitemeyer, \& Sparks, 2011), the SDT model developers have not operationalized altruistic motivation as a unique type of motivation. Based on this study, this altruistic motivation is the motivation to do something selfless in order to advance others' means, opportunities and social, emotional and cognitive wellbeing. While intrinsic, extrinsic and altruistic motives explained the pursuit of the degree, it as individual attributes and familial integration that explained the persistence (see Figure 1).

Tinto's (1993) model has been frequently used to explain doctoral persistence. Tinto $(1975,1993)$ suggested that persistence is influenced by (a) individual candidate's characteristics and prior experiences and (b) "integration" or institutional variables. "[T]he more central one's membership is to the mainstream of institutional life the more likely, other things being equal, is one to persist" (Tinto, 1987, p. 123). In other words, if candidates feel they "fit", they are more likely to persist, and one of the most consistently identified factors of doctoral persistence is candidates' integration into the university, especially via interaction with the faculty and a match between candidates and their faculty advisors (de Valero, 2001; Gardner, 2009; Jimenez, 2011; Maher et al., 2004; Smith et al., 2006). While this study uncovered that candidates' attributes (self-reliance, work ethic, and self-determination) derived from their experience of growing up in poverty were central to doctoral persistence, social and academic integration into the university was not an important factor in explaining doctoral persistence with the population under study. As we are discussing individuals from backgrounds of poverty, it is also significant to note that economic integration, the "degree to which candidate's financial needs are met while pursuing the doctorate" (Wao \& Onwuegbuzie, 2011, p. 117) is another factor often important to doctoral persistence and related to university integration was not of high importance to this population.

Thus, Tinto's (1993) theory was only partially confirmed, and findings of this research uncovered that the phenomenon of familial integration, defined as the degree to which the candidate's sense of connectedness with family members is met while pursuing the doctorate, served to provide motivation to not only pursue a doctoral degree but also to persist. Although the role of a supportive family has been linked to doctoral persistence (Lott et al., 2009; Price, 2006), this phenomenon of familial integration has not been operationalized or identified as a central factor in explaining doctoral persistence. In operationalizing this construct, it is important to recognize that this concept not only includes the maintaining of familial relationships and relatedness (a sense of belonging and care) but also includes the "fit" between the degree and family values and the altruistic motive to see offspring overcome the generational effect of poverty and have means and opportunities not afforded when growing up in poverty. This was exhibited by participants in this study through their giving up of their own desires and needs to ensure children felt cared for and valued, doing so intentionally, during the degree, postponing the degree to ensure family was cared for, and choosing to pursue the degree to ensure family was materially provided for and 
offspring were afforded opportunities that would not be offered to them if they were living in poverty.

\section{Limitations, Delimitations, and Future Research}

More research is needed with doctoral candidates from backgrounds of poverty as well as from diverse backgrounds to confirm the constructs of altruistic motivation and familial integration and their roles in doctoral pursuit and persistence. As the sample was drawn from a private, religious affiliated institution, the role of personal faith as a turning point for positive life span trajectory also needs further investigation. This turning point may not be generalizable to doctoral candidates from non-religiously affiliated institutions. As the sample was drawn from a specific discipline, the recommendations and implications derived from this study may have limited application to individuals outside of doctorate of education programs, especially since research demonstrates different completion rates, time to completion, and program characteristics based on different disciplines (Golde, 2005; Nerad \& Miller, 1996; Rodwell \& Neuman, 2008). Further, the results and their implications are limited by the demographics of the sample, which consisted of ten $(83.3 \%)$ Caucasians. Moreover, as the study focused on candidates who persisted to candidacy, this study did not consider the persistence into a conferred degree. Additional research that includes individuals from more diverse backgrounds outside of the field of education is needed. Further, this study should be replicated with a sample whose degrees are conferred as well as a sample that dropped out.

\section{Implications}

Based on this research, there are implications for universities desiring to support the persistence of candidates who come from backgrounds of poverty. Although candidates have an understanding of the hard work and the sacrifices required for a doctoral program, providing information to candidates and their families about the time, money, organizational skills, and intellectual rigor required to complete a doctoral program in a family orientation prior to the program beginning may help them clarify any misconceptions about the new process and further prepare the candidates and their family for the doctoral journey. As the family is a central asset in the process, it is important to consider and include them at the beginning of the process as having realistic expectation about requirements when beginning a doctoral program decrease the candidates' and the families' feelings of frustration, confusion, and disappointment, feelings often associated with doctoral attrition (Lovitts, 2001; West, 2014). Continuing to include the family throughout the process may also be important. With a plethora of web technologies (e.g., wikis, Facebook, Twitter), universities can create forums for doctoral candidates and their families to receive updates about the program and seek support during the program. Invitations to school social functions and other on-campus events can be extended to doctoral candidates and their families. Finally, as time with family is important, offer courses in a convenient format that allows candidates to avoid major disruptions in family time. This may include online, evening, and weekend courses.

\section{Conclusion}

Earning a doctoral degree, a terminal degree in one's field, is generally considered to be the pinnacle of academic achievement. For individuals from contexts of childhood poverty, this goal, if even considered, might have seemed at one time an impossible dream. The literature demonstrates that the journey towards completing a doctorate is a complex milieu of factors (RockinsonSzapkiw \& Spaulding, 2014), and when this intricate exchange of factors is compounded by the disadvantages of childhood poverty, the demonstration of persistence among students is even more remarkable. The doctoral candidates who participated in this study provided us with the data needed to extend several important theories related to self-determination, persistence, and 
resilience. The sociocultural context of this research afforded us the opportunity to examine childhood poverty, with a specific focus on investigating the complex relationship between poverty and self-determination to arrive at the precipice of doctoral candidacy and the necessary resilience mechanisms associated with doctoral persistence. The resulting theoretical model (see Figure 1) seeks to provide a visual image that accounts for these relationships, which begin with significant losses in childhood that are subsequently transformed into or expressed as positive attributes such as resilience, self-determination, faith, and motivation in later adulthood. These attributes are significant factors in shaping the doctoral experiences of students who persevered despite experiences of poverty in childhood.

Most significantly, this study produced two new constructs contributing to the empirical and theoretical literature addressing persistence. The first, specifically related to doctoral persistence and attrition, is the phenomenon of familial integration, which we define as the degree to which the candidate's sense of connectedness with family members is met while pursuing the doctorate. The second, which may advance SDT, is the concept of altruistic motivation, the motivation to do something selfless in order to advance others' means, opportunities, and social, emotional and cognitive well-being. Future research examining different populations in varying contexts is necessary, but we believe the findings presented here provide a beginning point for further study and discussion on the complex relationships between poverty, motivation, and resilience as they relate to doctoral persistence.

\section{References}

Allen, I. E., \& Seaman, J. (2010). Learning on demand: Online education in the United States, 2009. Babson Park, MA: Babson Survey Research Group. Retrieved from http://sloanconsortium.org/sites/default/files/pages/learningondemand-7.pdf

Bair, C. R. (1999). Doctoral student attrition and persistence: A meta-synthesis. (Doctoral dissertation, Loyola University, Chicago, 1999). Dissertation Abstracts International.

Bean, J. P. \& Metzner, B. S. (1985). A conceptual model of nontraditional student attrition. Review of Educational Research, 55, 485-540.

Berelson, B. (1960). Graduate education in the United States. The University of Michigan: McGraw Hill.

Black, A. E., \& Deci, E. L. (2000). The effects of instructors' autonomy support and students' autonomous motivation on learning organic chemistry: A self-determination theory perspective. Science Education, 84, 740-756.

Boss, P. (2004). Ambiguous loss research, theory, and practice: Reflections after 9/11. Journal of Marriage and Family, 66, 551-566.

Bowen, W., \& Rudenstine, N. (1992). In pursuit of the Ph.D. Princeton, NJ: Princeton University Press.

Butner, B., Caldera, Y., Herrera, P., Kennedy, F., Frame, M., \& Childers, C. (2001). The college choice process of African American and Hispanic women: Implications for college transitions. Journal of College Orientation and Transition, 9(1), 24-32.

Cabrera, A. F., \& La Nasa, S. M. (2000). Understanding the college choice of disadvantaged students. San Francisco, CA: Jossey-Bass.

Cefai, C. (2004). Pupil resilience in the classroom: A teacher's framework. Emotional and Behavioral Difficulties, 9(3), 149-170.

Clauss-Ehlers, C. S. (2008). Sociocultural factors, resilience, and coping: Support for a culturally sensitive measure of resilience. Journal of Applied Developmental Psychology, 29, 197-212.

deCharms, R. (1968). Personal causation. New York, NY: Academic Press. 
Deci, E. L., \& Ryan, R. M. (1985). Intrinsic motivation and self-determination in human behavior. New York, NY: Plenum Press.

Deci, E. L., \& Ryan, R. M. (2000). Intrinsic and extrinsic motivations: Classic definitions and new directions. Contemporary Educational Psychology, 25(1), 54-67. doi: 10.1006/ceps.1999.1020

Deci, E. L., \& Ryan, R. M. (2008). Self-determination theory, human motivation, development, and health. Canadian Psychology, 49(3), 182-185. doi: 10.1037/a0012801

Deci, E. L., Vallerand, R. J., Pelletier, L. G., \& Ryan, R. M. (1991). Motivation and education: The selfdetermination perspective. Educational Psychologist, 26, 325-346.

Deci, E. L., \& Vansteenkiste, M. (2004). Self-determination theory and basic need satisfaction: Understanding human development in positive psychology. Ricerche di Psichologia, 27, 17-34.

de Valero, F. Y. (2001). Departmental factors affecting time-to-degree and completion rates of doctoral students at one land-grant research institution. The Journal of Higher Education, 72(3), 341-367.

Doll, B. \& Lyon, M. A. (1998). Risk and resilience: Implications for the delivery of educational and mental health services in the schools. School Psychology Review, 27, 348-363.

Duncan, G. J., \& Magnuson, K. (2011). The long reach of early childhood poverty. Pathways, Winter, 2227.

Earl-Novell, S. (2006). Determining the extent to which program structure features and integration mechanisms facilitate or impede doctoral candidate persistence in mathematics. International Journal of Doctoral Studies, 1, 45-57. Retrieved from http://www.ijds.org/Volume1/IJDSv1p045057Ear116.pdf

Evans, G. W., \& Schamberg, M. A. (2009). Childhood poverty, chronic stress, and adult working memory. Proceedings of the National Academy of Sciences, 106(16), 6545-6549.

Gardner, S. K. (2009). Student and faculty attributions of attrition in high and low-completing doctoral programs in the United States. Higher Education, 58, 97-112.

Gardner, S. K., \& Holley, K. A. (2011). Those invisible barriers are real: The progression of firstgeneration candidates through doctoral education. Equity \& Excellence in Education, 44(1), 77-92. doi:10.1080/10665684.2011.529791

Garmezy, N. (1971). Vulnerability research and the issue of primary prevention. American Journal of Orthopsychiatry, 41(1), 101-116.

Golde, C. M. (2005). The role of the department and discipline in doctoral student attrition: Lessons from four departments. The Journal of Higher Education, 76(6), 669-700.

Groen, J., Jakubson, G. H., Ehreneberg, R. G., Condie, S., \& Yung Hsu Liu, A. (2008, April). Program design and candidate outcomes in graduate education. Economics of Education Review, 27(2), 111-124.

Grotberg, E. H. (2003). Resilience for today: Gaining strength from adversity. Westport, CT: Praeger Publishers.

Hernandez, D. J. (2011). Double jeopardy: How third-grade reading skills and poverty influence high school graduation. Retrieved from http://fcd-us.org/sites/default/files/DoubleJeopardyReport.pdf

Herzig, A. H. (2002). Where have all the doctoral candidates gone? Participation of doctoral candidates in authentic mathematical activity as a necessary condition for persistence toward the Ph.D. Educational Studies in Mathematics, 50, 177-212.

Hoffer, T. B., Sederstrom, S., Selfa, L., Welch, V., Hess, M., Brown, S., \& Guzman-Barron, I. (2003). Doctorate recipients from United States universities: Summary report 2002. Chicago, IL: National Opinion Research Center.

Horn, L. J., \& Chen, X. (1998). Toward resiliency: At-risk students who make it to college. Washington, DC: Office of Educational Research and Improvement, U.S. Department of Education. 
Hoskins, C. M., \& Goldberg, A. D. (2005). Doctoral candidate persistence in counselor education programs: Candidate-program match. Counselor Education and Supervision, 44(3), 175-188.

Hossler, D., Schmit, J., \& Vesper, N. (1999). Going to college. How social, economic, and educational factors influence the decisions students make. Baltimore, MD: Johns Hopkins University Press.

Ivankova, N. V., \& Stick, S. L. (2007). Candidates' persistence in a distributed doctoral program in educational leadership in higher education: A mixed methods study. Research in Higher Education, 48(1), 93-135. doi:10.1007/s11162-006-9025-4

Jimenez, C. (2011). Predictors of well-being and depression among Latino college students. Unpublished dissertation, University of Houston, United States - Texas. Retrieved from Dissertations \& Theses: Full Text. (Publication No. AAT 3485056).

Lincoln, Y., \& Guba, E. (1985). Naturalistic inquiry. Newbury Park, CA: Sage.

Lott, J., Gardner, S. K., \& Powers, D. A. (2009). Doctoral student attrition in the STEM fields: An exploration of event history analysis. The Journal of College Student Retention, 11, 247-266.

Lovitts, B. E. (2001). Leaving the ivory tower: The causes and consequences of departure from doctoral study. Lanham, UK: Rowman \& Littlefield Publishers.

Luthar, S. S., Cicchetti, D., \& Becker, B. (2000). The construct of resilience: A critical evaluation and guidelines for future work. Child Development, 71(3), 543-562.

Maher, M. A., Ford, M. E., \& Thompson, C. M. (2004). Degree progress of women doctoral students: Factors that constrain, facilitate, and differentiate. The Review of Higher Education, 27(3), 385-408.

Mason, M. (2012). Motivation, satisfaction, and innate psychological needs. International Journal of Doctoral Studies, 7, 259-277. Retrieved from http://ijds.org/Volume7/IJDSv7p259-277Mason0345.pdf

Masten, A. S. (1994). Resilience in individual development: Successful adaptation despite risk and adversity. In M. C. Wang \& E. Gordon (Eds.), Educational resilience in inner city America: Challenges and prospects. Hillsdale, NJ: Erlbaum

Masten, A. S., Best, K. M., \& Garmezy, N. (1990). Resilience and development: Contributions from the study of children who overcome adversity. Development and Psychopathology, 2, 425-44.

McQueen, H. (2009). Integration and regulation matters in educational transition: A theoretical critique of retention and attrition models. British Journal of Educational Studies, 57, 70-88.

Nerad, M., \&Miller, D. (1996). Increasing student retention in graduate and professional programs. In J. Haworth (Ed.), New Directions for Institutional Research, 1996(92), 61-76.

Nettles, M. T., \& Millett, C. M. (2006). Three magic letters: Getting to Ph.D. Baltimore, MD: John Hopkins University Press.

O'Connor, N. (2009). Hispanic origin, socio-economic status, and community college enrolment, Journal of Higher Education, 80, 121-145.

Pavey, L. J., Greitemeyer, T., \& Sparks, P. (2011). Highlighting relatedness promotes prosocial motivation and behavior. Personality and Social Psychology Bulletin, 37, 905-917.

Perna, L. W. (2004). Understanding the decision to enroll in graduate school: Sex and racial/ethnic group differences. The Journal of Higher Education, 75(3), 487-527.

Patton, M. Q. (1990). Qualitative evaluation and research methods (2nd ed.). Newbury Park, CA: Sage.

Patterson, C. J., \& Hastings, P. D. (2007) Socialization in the context of family diversity. In J. E. Grusec \& P. D. Hastings (Eds.), Handbook of socialization (pp. 328 - 351). NY: Guildford Press

Price, J. (2006). Does a spouse slow you down? Marriage and graduate student outcomes. Unpublished manuscript. 
Ramburuth, P., \& Hartel, C. E. J. (2010). Understanding and meeting the needs of candidates from low socioeconomic status backgrounds. Multi-cultural Education \& Technology Journal, 4(3), 153162. doi: $10.1108 / 17504971011075156$

Ready, D. (2010). Socioeconomic disadvantage, school attendance, and early cognitive development: The differential effects of school exposure. Sociology of Education, 84(4), 271-286.

Rockinson-Szapkiw, A. J. \& Spaulding, L. S. (Eds.) (2014). Navigating the doctoral journey: A handbook of strategies for success. Lanham, MD: Rowman \& Littlefield.

Rodwell, J., \& Neumann, R. (2008). Predictors of timely doctoral completions by type of attendance: The utility of pragmatic approach. Journal of Higher Education Policy and Management, 301(1), 6576.

Roth, G. (2008). Perceived parental conditional regard and autonomy support as predictors of young adults' self- versus other-oriented pro-social tendencies. Journal of Personality, 76, 513-534.

Rudestam, K. E., \& Newton, R. R. (2007). Surviving your dissertation: A comprehensive guide to content and process. Los Angeles, CA: SAGE Publications.

Rutter, M. (1985). Resilience in the face of adversity: Protective factors and resistance to psychiatric disorder. British Journal of Psychiatry, 147, 598-611.

Rutter, M. (1987). Psychosocial resilience and protective mechanisms. American Journal of Orthopsychiatry, 57(3), 316-331.

Rutter, M. (1999). Resilience concepts and findings: Implications for family therapy. Journal of Family Therapy, 21(2), 119-144.

Ryan, R. M., \& Connell, J. P. (1989). Perceived locus of causality and internalization: Examining reasons for acting in two domains. Journal of Personality and Social Psychology, 57, 749-761.

Ryan, R. M., \& Deci, E. L. (2000). Self-determination theory and the facilitation of intrinsic motivation, social development, and well-being. American Psychologist, 55, 68-78.

Ryan, R. M., \& Deci, E. L. (2006). Self-regulation and the problem of human autonomy: Does psychology need choice, self-determination, and will? Journal of Personality, 74, 1557-1586.

Ryan, R. M., \& Deci, E. L. (2008a). A self-determination theory approach to psychotherapy: The motivational basis for effective change. Canadian Psychology, 49, 186-193.

Ryan, R. M., \& Deci, E. L. (2008b). From ego-depletion to vitality: Theory and findings concerning the facilitation of energy available to the self. Social and Personality Psychology Compass, 2, 702717.

Ryan, R. M., \& Niemiec, C. P. (2009). Self-determination theory in schools of education: Can an empirically supported framework also be critical and liberating? Theory and Research in Education, 7, 263-272.

Sirin, S. R. (2005). Socioeconomic status and academic achievement: A meta-analytic review of research. Review of Educational Research, 75, 417-453.

Smith, R. L., Maroney, K., Nelson, K. W., Abel, A. L., \& Abel, H. S. (2006). Doctoral programs: Changing high rates of attrition. Humanistic Counseling, Education, and Development, 45, 17-31.

Spaulding, L. S. (2009). "Education will be our Mother": An exploration of resilience mechanisms relating to the educational persistence of Sudanese refugees (Doctoral dissertation). Retrieved from ProQuest. (AAT 3388398)

Spaulding, L.S. \& Rockinson-Szapkiw, A. J. (2012). Hearing their voices: Factors doctoral candidates attribute to their persistence. International Journal of Doctoral Studies, 7, 199-219. Retrieved from http://ijds.org/Volume7/IJDSv7p199-219Spaulding334.pdf

Strauss, A., \& Corbin, J. (1990). Basics of qualitative research: Grounded theory procedures and techniques (2nd ed.). Newbury Park, CA: Sage. 
Strenze, T. (2007). Intelligence and socioeconomic success: A meta-analytic review of longitudinal research. Intelligence, 35, 401-426.

Terenzini, P. T., Springer, L., Yaeger, P. M., Pascarella, E. T., \& Nora, A. (1996). First-generation college candidates: Characteristics, experiences, and cognitive development. Research in Higher Education, 37(1), 1-22.

Tinto, V. (1975). Dropout from higher education: A theoretical synthesis of recent research. Review of Educational Research, 45(1), 89-125.

Tinto, V. (1987). Leaving college. Chicago, IL: The University of Chicago Press.

Tinto, V. (1993). Leaving college: Rethinking the causes and cures of candidate attrition (2nd ed.). Chicago, IL: The University of Chicago Press.

Tinto, V. (2006-2007). Research and practice of student retention: What next? Journal of College Student Retention: Research, Theory \& Practice, 8(1), 1-20.

Tavernise, S. (2012). Education gap grows between rich and poor, studies say. The New York Times. Retrieved from http://www.nytimes.com/2012/02/10/education/education-gap-grows-between-richand-poor-studies-show.html?pagewanted=all

UNICEF Innocenti Research Centre. (2012). Measuring child poverty: New league tables of child poverty in the world's rich countries (Innocenti Report Card 10). Florence, Italy: UNICEF Innocenti Research Centre.

Vansteenkiste, M., Simons, J., Lens, W., Sheldon, K. M., \& Deci, E. L. (2004). Motivating learning, performance, and persistence: The synergistic effects of intrinsic goal contents and autonomysupportive contexts. Journal of Personality and Social Psychology, 87, 246-260.

Wao, H. O., \& Onwuegbuzie, A. J. (2011). A mixed research investigation of factors related to time to the doctorate in education. International Journal of Doctoral Studies, 6, 115-134. Retrieved from http://ijds.org/Volume6/IJDSv6p115-134Wao320.pdf

Werner, E. E., Bierman, J. M., \& French, F. E. (1971). The children of Kauai: A longitudinal study from the prenatal period to age ten. Honolulu, HI: University of Hawaii Press.

West, L.C. (2014). Communicating needs and nurturing familial relationships. In A. J. Rockinson-Szapkiw \& L. S. Spaulding (Eds.), Navigating the doctoral journey: A handbook of strategies for success. Lanham, MD: Rowman \& Littlefield.

Willis, B., \& Carmichael, K. D. (2011). The lived experience of late-stage doctoral candidate attrition in counselor education. The Qualitative Report, 16(1), 192-207.

Young, A., Johnson, G., Hawthorne, M., \& Pugh, J. (2011). Cultural predictors of academic motivation and achievement: A self-deterministic approach. College Candidate Journal 45(1), 151-163.

\section{Biographies}

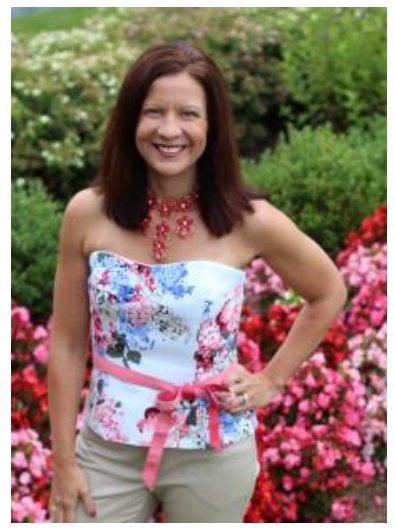

Amanda J. Rockinson-Szapkiw earned an Ed.D. in Distance Education, a M.A. in Counseling, and a B.S. in Elementary Education. She is an Associate Professor for the School of Education at Liberty University and teaches doctoral-level research and analysis and proposal development courses. Over the past five years, she has also served as the chair of doctoral research. Dr. Rockinson-Szapkiw is a board member for two international, humanitarian organizations, Freedom 4/24 and Global Mosaic International. Her research interests include educational technology and distance education and best practices for counselor education and trauma care in domestic and international settings. Dr. Rockinson Szapkiw, along with Dr. Spaulding, has also published nu- 
merous articles and presented nationally and internationally in the area of doctoral persistence. They recently published the co-edited book, Navigating the Doctoral Journey: A Handbook of Strategies for Success. Dr. Rockinson Szapkiw's development of a collaborative, online workspace to facilitate doctoral mentorship was recognized by Microsoft via a case study, resulted in a nomination for the Chronicles of Education Innovator award, and was awarded a Campus Technology innovator award.

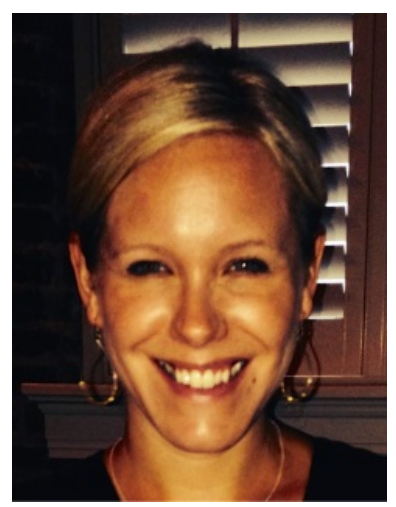

Lucinda S. Spaulding earned her Ph.D. in Special Education and Educational Psychology, M.Ed. in Special Education, and B.S. in Elementary Education. She is an Associate Professor in the School of Education at Liberty University where she teaches doctroal research courses and chairs dissertations. Dr. Spaulding is a board member of the Virginia Council for Exceptional Children and serves as co-editor of the association's journal. Dr. Spaulding's research interests include examining factors related to doctoral persistence, resilience in children and youth, specific learning disabilities and methods of best practice, and the history of special education.

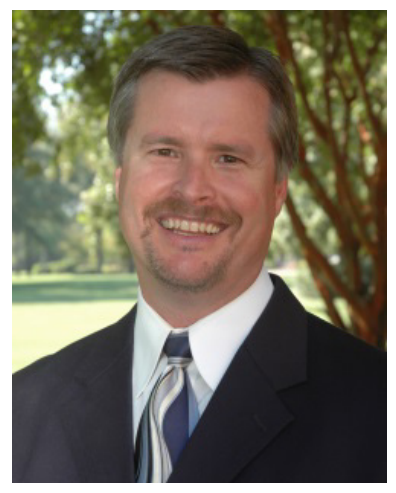

James A. Swezey is an associate professor for graduate education at Liberty University where he teaches courses on educational leadership, historical and theoretical foundations of educations, and qualitative research designs. He currently serves as the chair for qualitative dissertation research. He serves as a reviewer for various research journals and special interest groups associated with the American Educational Research Association. He is the associate editor for the ICCTE Journal and has published multiple articles and book chapters.

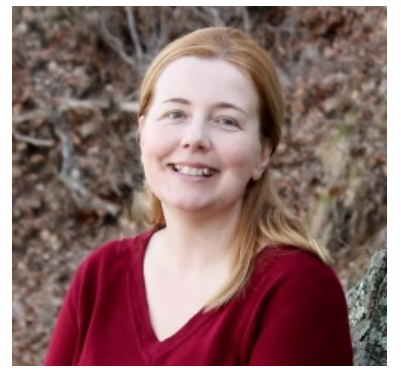

Carolyn J. Wicks earned her Ed.D. in Elementary Education, M.Ed. in Elementary Education, and B.S. in Elementary Education. She teaches courses in curriculum and instruction for the School of Education at Liberty University. She has taught in higher education for eleven years. Before entering higher education teacher preparation, Carolyn taught for many years in the Pacific Northwest: first as an elementary general education teacher and later as an ESL instructor supporting the literacy needs of refugees and immigrants. As a qualitative researcher, Carolyn's scholarly interests include best practices in technology and teaching, understanding factors of doctoral persistence, and motivating 21 st century students in various learning contexts. 